\title{
Histopathological Pattern of Endometrium: Hospital Based Study in Teaching Hospital, Batticaloa, Srilanka
}

\author{
Markandu Thirukumar ${ }^{1 *}$, Sinnathurai Ahilan² \\ ${ }^{1}$ Department of Clinical Science, Faculty of Health Care Science, Eastern University, Vantharumoolai, Sri Lanka \\ ${ }^{2}$ Batticaloa Teaching Hospital, Batticaloa, Sri Lanka \\ Email:*dr.thiru10@ya hoo.com
}

How to cite this paper: Thirukumar, M. and Ahilan, S. (2018) Histopathological Pattern of Endometrium: Hospital Based Study in Teaching Hospital, Batticaloa, Srilanka. Open Journal of Obstetrics and Gynecology, 8, 1015-1022.

https://doi.org/10.4236/ojog.2018.811102

Received: August 25, 2018

Accepted: September 14, 2018

Published: September 17, 2018

Copyright (c) 2018 by authors and Scientific Research Publishing Inc. This work is licensed under the Creative Commons Attribution International License (CC BY 4.0).

http://creativecommons.org/licenses/by/4.0/

\begin{abstract}
Introduction: Abnormal uterine bleeding, either due to organic or be dysfunctional cause, is a common gynaecological problems. Methods: A retrospective, cross sectional, hospital-based study was done for a period of five and a half years included 1884 samples which were taken by endosampling as well as by curetting for the evaluation of several gynaecological symptoms. Results: The age distribution ranges from 16 to 83 years. $12.8 \%$ of $(242 / 1884)$ samples were inadequate for a comprehensive diagnosis. The functional cause was the predominant in 1263 samples and organic causes were found in 379 sample. The menorrhagia is the commonest one and it is followed by post-menopausal bleeding and polymenorrhoea. Endometrial polyp was the predominant organic $(46.9 \%)$ cause followed by $(26.1 \%)$ simple endometrial hyperplasia without atypia. Most of the simple hyperplasia without atypia (49/99) and complex hyperplasia (10/28) also occurred in the same age group. Total 29 (1.5\%) cases of carcinoma of endometrium were found and it was common (13/29) in 50 - 59 years of age. It was noted that (5/29) carcinoma occurred in less than 39 years of age. Conclusion: This study shows that most of the patients fall in the age group of $40-49$ years. As the organic causes mostly found in this age group, endometrial cavity evaluation should be done more than 40 years of age. Further endometrial hyperplasia and carcinoma of the endometrium also occurs in less than 40 years of age. Therefore, clinical risk factors should be assessed and need of endometrial cavity should be individualised for better outcome.
\end{abstract}

\section{Keywords}

Abnormal Uterine Bleeding, Histopathological Pattern of the Endometrium 


\section{Introduction}

The uterine endometrium undergoes hormones driven cyclical changes of proliferation, differentiation, breakdown and regeneration [1]. Any alteration in its regularity, frequency of menses, duration of flow, and amount of blood loss, is called abnormal uterine bleeding (AUB); symptom and not a disease [2]. It affects not only her social and sexual life but also imposes economic burden to the women, her family and to the health system.

AUB may be due to organic or dysfunctional in nature [2]. Below the age of 20 years the disturbance is most likely to be a functional one. On the other hand, in active reproductive life an organic cause for bleeding is more likely, pregnancyrelated conditions being the most common. Again, functional disorders are common after the age of 40 years but the possibility of a benign or malignant growth must be excluded. After the menopause, a local organic cause often presents, possibly malignancy presents in $10 \%$ of the cases [2].

Dysfunctional Uterine Bleeding (DUB), caused by an ovulation or anovulation [3], is responsible for $80 \%$ of menorrhagia [4], and diagnosed after exclusion of all organic causes. It is mandatory in the evaluation of AUB in women older than 40 to 45 years of age, in younger women who are obese, and in those with a history of prolonged anovulation [5].

Diagnostic hysteroscopic biopsy is the gold standard for endometrial cavity evaluation to exclude endometrial hyperplasia or carcinoma. It can be done in outpatient clinic set up. But in dilation and curettage (D \& C), in $60 \%$ of cases, less than half of the uterine cavity is curetted, with the added risk of general anesthesia, infection and perforation [6] [7]. This has led to the advent of new and simple methods for endometrial sampling. Various devices are available such as Pipelle and vabra [8] [9]. The endometrial sampling can be used as an outpatient basis. It is cost effective and simple compared with D\&C [10]. However, there are still concerns regarding the adequacy of the sample obtained, non-sampling of focal intrauterine lesions [9].

\section{Materials and Methods}

This study was aimed to evaluate abnormal Uterine Bleeding in various age groups, clinical presentations and assess the histopathological pattern of the endometrium taken for endometrial evaluation it was a retrospective, cross-sectional study carried out in Teaching Hospital, Batticaloa for a period of five and a half years from January 2012 to June 2017. It included 1884 patients gynaecological specimens presented to histopathology laboratory to study the endometrial histo-pathology. The specimens were taken by endosampling as well as by dilatation and curetting for the evaluation of several symptoms and signs such as abnormal uterine bleeding, abdominal pain, lump, per vaginal whitish discharge.

Exclusion criteria; Biopsy samples from the genital tract other than endometrium and pregnancy were excluded from the study. The histopathological findings were classified as functional and organic causes. Functional causes included 
physiological cyclical changes as proliferative and secretory phases, atrophic and weakly proliferative endometrium, disordered proliferative endometrium, nonspecific degenerative changes. Organic causes included endometrial polyp, chronic endometritis, hyperplasia and carcinomas.

This research was approved by Ethics review committee of the faculty of Health Care Science, Eastern University, Sri Lanka. (EUSL/FHCS/ERC/2017/21)

Data were processed using SPSS version 21. Descriptive statistics methods were used to analyze the results as whole numbers, percentages, tables, and charts.

\section{Results}

A total of 1884 gynaecological patients' specimens were taken in this study. About 242 (12.8\%) specimens were inadequate for a comprehensive diagnosis. Remaining 1642 specimens were adequate for reporting.

Table 1 shows that age of the patients of this study ranges from 16 to 83 years. Most (41.3\%) of age group is between $40-49$ years. The study shows that functional cause was the predominant in 1263 samples (67\%) and organic causes were found in 379 samples $(20.12 \%)$.

Table 2 shows the Clinical presentation of different age groups. Most patients (87.5\%) who underwent this histopathological study were admitted due to abnormal bleeding pattern. Of that abnormal bleeding pattern, menorrhagia was the commonest $(45.1 \%)$ one and it is followed by post-menopausal bleeding (11.7\%) and polymenorrhoea (11.5\%). Apart from abnormal uterine bleeding pattern, patients presented with per vaginal whitish discharge (5.1\%), abdominal pain (6.2\%) and lump (1.2\%). Menorrhagia was the most common (51.4\%) cause among the age group between 40 - 49 years.

Majority of the functional causes were due to proliferative phase $(48.5 \%)$ of endometrium followed by secretory phase (37.2\%) of endometrium; Table 3. When the organic causes are considered (Table 4) it shows that endometrial polyp was the predominant organic (46.9\%) causes followed by simple endome.

Table 1. Distribution of age in years.

\begin{tabular}{ccc}
\hline Age group & Frequency & $\%$ \\
\hline $16-29$ & 145 & 7.7 \\
$30-39$ & 379 & 20.1 \\
$40-49$ & 778 & 41.3 \\
$50-59$ & 514 & 27.3 \\
$60-69$ & 55 & 2.9 \\
$70-79$ & 12 & 0.6 \\
$\geq 80$ & 1 & 0.1 \\
Total & 1884 & 100.0 \\
\hline
\end{tabular}


Table 2. Clinical presentation of different age group.

\begin{tabular}{ccccccccccc}
\hline \multirow{2}{*}{ Clinical presentation } & \multicolumn{7}{c}{ Age Category (In years) } & & Total & (\%) \\
\cline { 2 - 10 } & $16-29$ & $\mathbf{3 0}-\mathbf{3 9}$ & $\mathbf{4 0}-\mathbf{4 9}$ & $\mathbf{5 0}-\mathbf{5 9}$ & $\mathbf{6 0}-\mathbf{6 9}$ & $\mathbf{7 0}-\mathbf{7 9}$ & $\geq 80$ & & \\
\hline Menorrhagia & 56 & 164 & 437 & 187 & 6 & 0 & 0 & 850 & 45.1 \\
Metrorrhagia & 28 & 50 & 38 & 9 & 1 & 0 & 0 & 126 & 6.7 \\
Menometrorrhagia & 4 & 22 & 52 & 21 & 0 & 0 & 0 & 99 & 5.3 \\
Polymenorrhagia & 31 & 68 & 75 & 43 & 0 & 0 & 0 & 217 & 11.5 \\
Post-menopausal bleeding & 0 & 0 & 24 & 159 & 32 & 6 & 0 & 221 & 11.7 \\
Continuous bleeding & 5 & 8 & 50 & 44 & 0 & 0 & 0 & 107 & 5.7 \\
Oligomenorrhea & 7 & 12 & 10 & 0 & 0 & 0 & 0 & 29 & 1.5 \\
Whitish discharge & 6 & 23 & 35 & 18 & 11 & 3 & 1 & 97 & 5.1 \\
Lump & 1 & 2 & 10 & 6 & 1 & 2 & 0 & 22 & 1.2 \\
Abdominal pain & 7 & 30 & 47 & 27 & 4 & 1 & 0 & 116 & 6.2 \\
Total & 145 & 379 & 778 & 514 & 55 & 12 & 1 & 1884 & 100.0 \\
Percentage (\%) & 7.7 & 20.1 & 41.3 & 27.3 & 2.9 & 0.6 & 0.1 & 100.0 & \\
\hline
\end{tabular}

Table 3. Distribution of the functional causes.

\begin{tabular}{ccc}
\hline Functional causes & Frequency & $\%$ \\
\hline Proliferative phase & 613 & 48.5 \\
Secretory phase & 470 & 37.2 \\
Atrophic endometrium & 94 & 7.4 \\
Disordered proliferative & 43 & 3.4 \\
Non-specific degenerative changes & 43 & 3.4 \\
Total & 1263 & 100.0 \\
\hline
\end{tabular}

Table 4. Distribution of organic causes.

\begin{tabular}{ccc}
\hline Organic causes & Frequency & $\%$ \\
\hline Simple endometrial hyperplasia without atypia & 99 & 26.1 \\
Complex hyperplasia & 28 & 7.4 \\
Endometrial polyp & 178 & 46.9 \\
Endometritis (Acute or Chronic) & 45 & 11.9 \\
Carcinoma & 29 & 7.7 \\
Total & 379 & 100.0 \\
\hline
\end{tabular}

Trial hyperplasia without atypia (26.1\%). Most of the endometrial polyps (72/178) occurred in the age group of 40 - 49 of years. Most of the simple hyperplasia without atypia (49/99) and complex hyperplasia (10/28) also occurred in the same age group.

This study showed that total 29 (1.5\%) cases of carcinoma of endometrium were found. Carcinoma was common (13/29) in 50 - 59 years of age (Table 5). It 
Table 5. Histopathological pattern versus age distribution.

\begin{tabular}{|c|c|c|c|c|c|c|c|c|c|}
\hline & \multicolumn{7}{|c|}{ Age Category } & \multirow[t]{2}{*}{ Total } & \multirow[t]{2}{*}{$(\%)$} \\
\hline & $16-2$ & $30-3$ & $40-4$ & $50-5$ & $50-6$ & $70-79$ & $\geq 80$ & & \\
\hline Proliferative phase & 56 & 137 & 243 & 172 & 5 & 0 & 0 & 613 & 32.5 \\
\hline Secretory phase & 45 & 121 & 227 & 76 & 0 & 1 & 0 & 470 & 24.9 \\
\hline Atrophic endometrium & 4 & 12 & 37 & 34 & 7 & 0 & 0 & 94 & 5.0 \\
\hline $\begin{array}{l}\text { Disordered proliferative } \\
\text { endometrium }\end{array}$ & 1 & 4 & 20 & 16 & 2 & 0 & 0 & 43 & 2.3 \\
\hline $\begin{array}{c}\text { Non-specific degenerative } \\
\text { changes }\end{array}$ & 4 & 3 & 17 & 18 & 0 & 1 & 0 & 43 & 2.3 \\
\hline $\begin{array}{c}\text { Simple endometrial } \\
\text { hyperplasia without atypia }\end{array}$ & 7 & 17 & 49 & 23 & 3 & 0 & 0 & 99 & 5.3 \\
\hline Complex hyperplasia & 4 & 3 & 10 & 8 & 1 & 2 & 0 & 28 & 1.5 \\
\hline Endometrial polyp & 5 & 42 & 72 & 50 & 8 & 1 & 0 & 178 & 9.4 \\
\hline $\begin{array}{c}\text { Endometritis } \\
\text { (Acute or Chronic) }\end{array}$ & 3 & 7 & 15 & 13 & 3 & 3 & 1 & 45 & 2.4 \\
\hline Carcinoma & 2 & 3 & 4 & 13 & 5 & 2 & 0 & 29 & 1.6 \\
\hline Inadequate tissue & 14 & 30 & 84 & 91 & 21 & 2 & 0 & 242 & 12.8 \\
\hline Total & 145 & 379 & 778 & 514 & 55 & 12 & 1 & 1884 & 100 \\
\hline Percentage (\%) & 7.7 & 20.1 & 41.3 & 27.3 & 2.9 & 0.6 & 0.1 & & \\
\hline
\end{tabular}

was unexpectedly noted that $(5 / 29)$ carcinoma occurred in less than 39 years of age. In the meantime, $2.4 \%$ of the total analyzed sample had either acute or chronic endometritis during the same study period.

\section{Discussion}

This study shows menorrhagia is the commonest (45.1\%) abnormal bleeding pattern followed by post-menopausal bleeding (11.7\%) and polymenorrhoea. (11.5\%). In a study by Bhosle (2010) maximum incidence of menorrhagia was found in 53.3\% of cases [11]. Mahapatra et al. [12] reported that menorrhagia in $48.6 \%$ of cases and polymenorrhoea accounts for $10 \%$ of cases.

This study shows $67 \%$ patients had functional causes. Majority of the functional causes were due to proliferative phase (48.5\%) of endometrium followed by secretary phase (37.2\%) of endometrium. A study by Mahapatara et al. shows that proliferative endometrium and secretary endometrium were seen in $45.7 \%$ and $30 \%$ of the cases. The higher incidence of the secretory phase (37.2\%) in this study can be attributed to ingestion of hormonal treatment, progesterone, taken for menstrual irregularities before undergoing endometrial biopsy procedure.

This study shows that $12.8 \%$ of $(242 / 1884)$ samples were inadequate for a comprehensive diagnosis while the study by Kaul et al. $8 \%$ had insufficient sample [13].

This study shows that 379 patients (20.12\% of the total patients) had organic 
causes. $46.9 \%$ of the organic causes were due to endometrial polyp while the simple endometrial hyperplasia without atypia constitutes $26.1 \%$. According to Bhosle, $17.8 \%$ of the organic causes were due to simple hyperplasia without atypia [14]. Bharti study found that $78.26 \%$ had simple hyperplasia without atypia and $13.04 \%$ had complex hyperplasia without atypia. According to Kuala al $8 \%$ had polyp, $18 \%$ had hyperplasias and $10 \%$ had carcinomas [13].

This study showed that carcinoma of endometrium was also found in 29 patients (7.7\% of the organic causes). Carcinoma was common (13/29) in $50-59$ years of age. In study by Kaul, $3 \%$ of endometrial cancer cases were observed [13]. It was unexpectedly noted in this study that (5/29) carcinoma occurred in less than 39 years of age.

Khan R, et al. [15] has shown endometrial hyperplasia is the commonest histopathological diagnosis in $20.5 \%$ cases, all were simple glandular hyperplasia. In a similar study, $18.3 \%$ cases were diagnosed as having hyperplasia of different types and two thirds of it fell in the perimenopausal ag group [16]. A similar trend of $24.7 \%$ endometrial hyperplasia cases has been observed by Muzzafar M et al. [17]. A variable incidence, from $6.66 \%$ to $15 \%$, of endometrial hyperplasia can be seen in different studies [18] [19] [20].

The variation on the incidence of carcinoma or its premalignant conditions could be attributed to difference in socioeconomic status and occurrence of risk factors like obesity, diabetes, life style and early diagnosis. Identification of endometrial hyperplasia is important as it is thought to be a precursor of endometrial carcinoma. The incidence of endometrial hyperplasia peaks around perimenopausal and postmenopausal women [21].

\section{Conclusions}

This study showed that most of the patients fall in the age group of 40 - 49 years. The organic causes were mostly found in this age group. Therefore, endometrial cavity evaluation should be done at more than 40 years of age. Further endometrial simple and complex hyperplasia, which is the precursor of malignancy and carcinoma of the endometrium, also occurs in less than 40 years of age. Therefore, clinical risk factors should be assessed and need of endometrial cavity should be individualised. It will increase the detection rate of endometrial malignancy for better outcome. It is to be noted that $242(12.8 \%)$ specimens were inadequate for a comprehensive diagnosis. Several of these specimens were obtained in dilation and curettage under general anesthesia. Thus, those patients were subjected for unnecessary and risky process. Therefore, clear indication must be established before embarking dilation and curettage.

The finding of this study has been already validated in several similar previous studies. However, this is the first published study from this region of Sri Lanka. It again reconfirms the preexisting knowledge.

\section{Acknowledgements}

I wish to express my sincere gratitude to Dr. Ibralebbe, Director, Teaching Hos- 
pital, Batticaloa for providing me opportunity to do this research in Teaching Hospital, Batticaloa. Sincerely thank to my research assistant Dr Hemika for tired less work. I also wish to express my gratitude to the officials and other staff members of Teaching Hospital, Batticaloa who rendered their help during this research period

\section{Conflicts of Interest}

The authors declare no conflicts of interest regarding the publication of this paper.

\section{References}

[1] Tavassoli, F.A. and Devilee, P., Eds. (2003) Tumors of the Uterine Corpus. In: WHO Classifications of Tumours. Pathology and Genetics of Tumors of the Breast and Female Genital Organs, IARC Press, Lyon, 221-232.

[2] Kumar, P. and Malhotra, N. (2008) Jeffcoate's Principles of Gynaecology. 7th Edition, JBMP, India, 598-616.

[3] Shwayder, J.M. (2000) Pathophysiology of Abnormal Uterine Bleeding. Obstetrics and Gynecology Clinics of North America, 27, 219-234.

https://doi.org/10.1016/S0889-8545(00)80017-0

[4] Parveen, F. and Hashim, H.A. (1999) Dysfunctional Uterine Bleeding: A Histopathology Study. Journal of the College of Physicians and Surgeons Pakistan, 9 , 318-320.

[5] Edward, R.G. (2007) Endometrial Bleeding. Human Reproduction Update, 13, 421-431. https://doi.org/10.1093/humupd/dmm001

[6] Telner, D.E. and Jakubovicz, D. (2007) Approach to Diagnosis and Management of Abnormal Uterine Bleeding. Canadian Family Physician, 53, 58-64.

[7] Clark, T.J. and Gupta, J.K. (2002) Endometrial Sampling of Gynaecological Pathology. The Obstetrician and Gynaecologist, 4, 169-174. https://doi.org/10.1576/toag.2002.4.3.169

[8] Vigod, S.N. and Stewart, D.E. (2002) Management of Abnormal Uterine Bleeding by Northern, Rural and Isolated Primary Care Physicians: PART I-How Are We Doing? BMC Women Health, 2, 10. https://doi.org/10.1186/1472-6874-2-10

[9] Brand, A., Duduc-Lissoir, J., Ehlen, T.G. and Plante, M. (2000) Diagnosis of Endometrial Cancer in Women with Abnormal Vaginal bleeding. SOGC Clinical Practice Guidelines, 22, 102-104.

[10] Fakhar, S., Saeed, G., Khan, A.H. and Alam, A.Y. (2008) Validity of Pipelle Endometrial Sampling in Patients with Abnormal Uterine Bleeding. Annals of Saudi Medicine, 28, 188-191. https://doi.org/10.4103/0256-4947.51721

[11] Bhosle, A. and Fonseca, M. (2010) Evaluation and Histopathological Correlation of Abnormal Uterine Bleeding in Perimenopausal Women. Bombay Hospital Journal, 52, 69-72.

[12] Mahapatra, M. and Mishra, P. (2015) Clinicopathological Evaluation of Abnormal Uterine Bleeding. Journal of Health Research and Reviews, 2, 45-49. https://doi.org/10.4103/2394-2010.160904

[13] Kaul, I., Kalsi, M., Anand, A.K., Jad, R. and Menia, V. (2012) Transvaginal Sonography versus Histopathology in Postmenopausal Bleeding: A Prospective Study. JK Science, 14, 129-133. 
[14] Bharti, B. and Satish, R.P. (2008) Feasibility, and Yield of Endometrial Biopsy Using Suction Curette Device for Evaluation of Abnormal Pre and Postmenopausal Bleeding. The Journal of Obstetrics and Gynecology of India, 58, 322-326.

[15] Khan, R., Sherwani, R., Rana, S., Hakim, S. and Jairajpuri, Z. (2016) Clinco-Pathological Patterns in Women with Dysfunctional Uterine Bleeding. Iranian Journal of Pathology, 11, 20-26.

[16] Baral, R. and Pudasini, S. (2011) Histopathological Pattern of Endometrial Samples in Abnormal Uterine Bleeding. Journal of Pathology of Nepal, 1, 13-16.

[17] Muzzafar, M., Akhtar, K.A.K., Yasmin, S., Rehman, M., Iqbal, W. and Khan, M.A. (2005) Menstrual Irregularities with Excessive Blood Loss: A Clinico-Pathological Correlation. Journal of Pakistan Medical Association, 55, 486-489.

[18] Silander, T. (1962) Hysteroscopy through a Transparent Rubber Balloon. Surgery, Gynecology \& Obstetrics, 114, 125.

[19] Abdullah, L.S. and Bondagji, N.S. (2011) Histopathological Pattern of Endometrial Sampling Performed for Abnormal Uterine Bleeding. Bahrain Medical Bulletin, 33, 1-6.

[20] Dexous, S., Labastida, R. and Arias, A. (1984) Hysteroscopy in Abnormal Uterine Bleeding. In: Segler, A.M., Ed., Linde Hysteroscopy. Principles and Practice, JB Lipponcott, Philadelphia, 121-134.

[21] Reed, S.D., Newton, K.M., Clinton, W.L., Epplein, M., Garacia, R., Allison, K., et al. (2009) Incidence of Endometrial Hyperplasia. American Journal of Obstetrics \& Gynecology, 200, 678.e1-678.e6. https://doi.org/10.1016/j.ajog.2009.02.032 